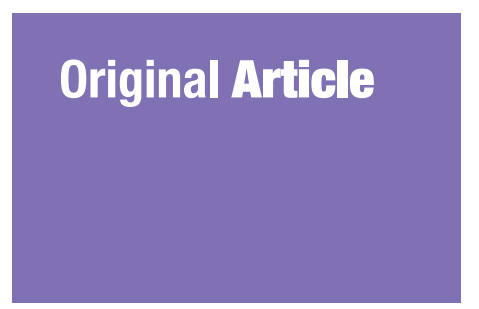

Submitted: 23 Nov 2015

Accepted: 2 Aug 2016

Online: 7 Dec 2016

\section{Supervised Versus Home Exercise Training Programs on Functional Balance in Older Subjects}

\section{Enas Fawzy Youssef, Alsayed Abd elhameed Shanb}

Physical Therapy Department, College of Applied Medical Sciences, University of Dammam, Alkhobar, Dammam City, Kingdom of Saudi Arabia

To cite this article: Enas Fawzy Y, Alsayed Shanb. Supervised versus home exercise training programs on functional balance in older subjects. Malays J Med Sci. 2016;23(6):83-93. http://dx.doi.org/10.21315/mjms2016.23.6.9

To link to this article: http://dx.doi.org/10.21315/mjms2016.23.6.9

\title{
Abstract
}

Background: Aging is associated with a progressive decline in physical capabilities and a disturbance of both postural control and daily living activities. The aim of this study was to evaluate the effects of supervised versus home exercise programs on muscle strength, balance and functional activities in older participants.

Methods: Forty older participants were equally assigned to a supervised exercise program (group-I) or a home exercise program (group-II). Each participant performed the exercise program for 35-45 minutes, two times per week for four months. Balance indices and isometric muscle strength were measured with the Biodex Balance System and Hand-Held Dynamometer. Functional activities were evaluated by the Berg Balance Scale (BBS) and the timed get-up-and-go test (TUG).

Results: The mean values of the Biodex balance indices and the BBS improved significantly after both the supervised and home exercise programs $(P<0.05)$. However, the mean values of the TUG and muscle strength at the ankle, knee and hip improved significantly only after the supervised program. A comparison between the supervised and home exercise programs revealed there were only significant differences in the BBS, TUG and muscle strength.

Conclusions: Both the supervised and home exercise training programs significantly increased balance performance. The supervised program was superior to the home program in restoring functional activities and isometric muscle strength in older participants.

Keywords: exercise training, muscle weakness, elderly

\section{Introduction}

The aging process usually affects all body systems and is commonly associated with functional changes in the neuromuscular, somatosensory, vestibular and visual systems $(1,2,3)$. Aging is generally associated with progressive declines in physical capabilities, psychological health (3) postural control and daily living activities (4). Balance is essential for maintaining postural control and performing various functional activities. Functional balance is the ability to maintain a stable position during various functional tasks. Proactive balance refers to an anticipation of a predicted disturbance as compensation for a disturbance (3). Balance disturbances are major epidemic geriatric health problems because they are associated with the fear of falling and mobility restrictions as well as causing substantial rates of mortality and morbidity (from 30\% to 60\%) among older subjects $(5,6,7)$. Balance impairments with functional dependencies can be improved with appropriate exercise interventions $(6,8)$.

A variety of exercises can be used to enhance coordination, proprioceptive sensation and balance acquisition, factors that are critically needed for functional dependency in older subjects (2, 9-12). The effect of exercise training mainly depends upon the mode, intensity and level of supervision during the exercise intervention (13). Few studies have reported 
findings where low intensity exercise training with $20 \%$ of a one-repetition maximum (1RMax) significantly improved balance performance greater than training with moderate intensity (50\% of 1 RMax) or high intensity $(80 \%$ of 1RMax) (14). A previous study has found that a supervised exercise program facilitates strong adaptations to exercise, particularly in older participants (15). The author considered a supervised exercise program as one of the most effective interventions as it introduces a well-structured progressive exercise program over a limited time (15). However, older people sometimes face major barriers in their adherence to exercise training programs due to a shortage of both availability and accessibility to transportation (16).

The literature supports home exercise programs as an alternative to supervised exercise programs because of their advantages (e.g. inexpensive, easy accessibility and organizational flexibility) (12). Previous studies have shown that supervised exercise programs are associated with significant improvements in balance performance and functional activities (17-21). On other hand, other studies have shown balance improvements and positive advantages with adherence to home exercise programs $(8,12$, 13). In addition, many studies have applied a combination of supervised and home exercises in the same program (22-25). In contrast, few studies have compared supervised exercise with home exercise programs $(3,4)$. There is currently no consensus about which program can provide greater improvements in older individuals. Therefore, the aim of this study was to compare the effectiveness of a supervised program with a home program on balance performance, functional activities and isometric muscle strength (IMS) in older participants.

\section{Materials and Methods}

\section{Study design: Experimental study design}

Subjects: Eighty (43 males and 37 females) older participants were selected from 350 independent individuals who were residing in nursing homes. Participants were selected according to the following inclusion criteria: aged $\geq 65$ years, as this is the recommended age for fall screening of older subjects; a recent history of falling in the previous six months; ambulatory, with or without a walking aid; and non-obese (body mass index $\left.<30 \mathrm{~kg} / \mathrm{m}^{2}\right)(4,23,26)$. Every participant achieved a Berg balance score of $\geq 21$ and $\leq 40$, indicating a moderate level of fall risk. This was measured during the initial evaluation during the recruitment period (4).

Out of the 80 volunteers, 40 participants were equally and randomly assigned to two groups by a blinded and independent research assistant who opened sealed envelopes containing a computer-generated randomisation card (Figure 1).

Exclusion criteria: Participants were excluded if they had participated in a regular exercise program in the previous two months. They were also excluded if they had a recent stroke, uncontrolled diabetes mellitus, severe hypertension, unstable cardiovascular diseases, advanced joint arthritis, significant dementia, blindness or deafness (4). Additionally, any participant who had received drugs that could affect balance performance (e.g. antidepressant, antispasmodic and sedative drugs) was excluded.

Group-I: Twenty (13 males and seven females) older participants with a mean age of $69.26 \pm 4.11$ years performed a supervised exercise program for 35 to 45 minutes, twice weekly for four months.

Group-II: Twenty (12 males and eight females) older participants with a mean age of $68.83 \pm 3.31$ years performed a home exercise program for 35 to 45 minutes, twice weekly for four months.

Ethical approval: Before starting any physical therapy interventions, the approval for this study was given by the Institutional Review Board of the Faculty of Physical Therapy, Cairo University. Both assessment and treatment procedures were conducted in the outpatient clinic of the Faculty of Physical Therapy. All participants signed a consent form prior to their participation in the study. Participants were also informed that the collected data would be submitted for publication.

\section{Instrumentation}

Biodex Balance System: We used the Biodex Balance System (Biodex Medical System Inc., Shirley, New York, USA), info@biodex. com, www.biodex.com. This system is a valid, reliable and objective tool for evaluating balance performance $(18,27)$.

Berg Balance Scale (BBS): The BBS is a reliable and valid case. It was used for assessment of functional activities in older adults $(6,28,29)$. 
Original Article | Supervised versus home exercise programs on older subjects

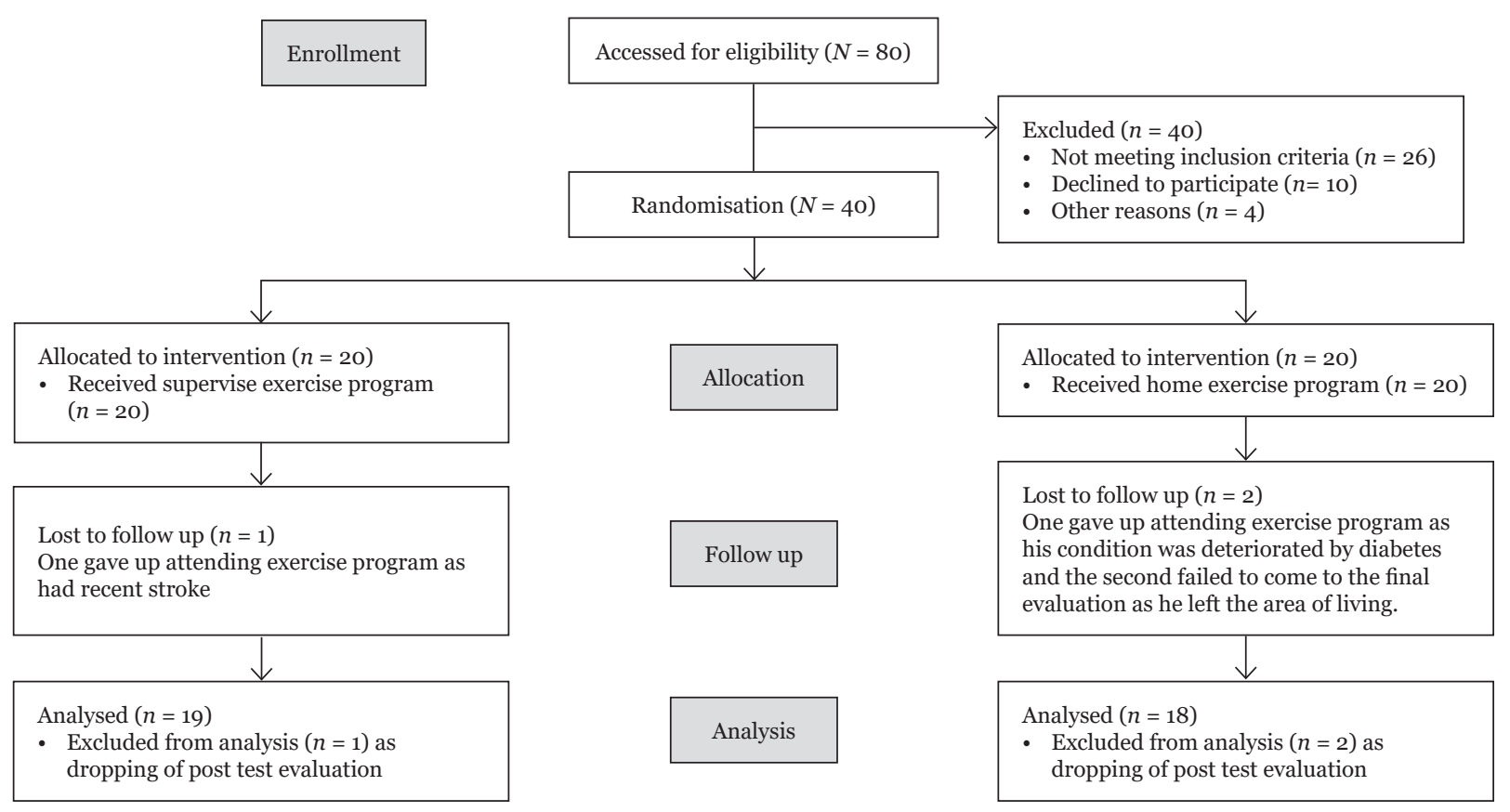

Figure 1. The flow chart of patients recruitment.

Timed get-up-and-go test (TUG): The TUG test is a satisfactory, sensitive and specific measure for basic functional activities in older subjects $(4,22)$.

Hand-Held Dynamometer: A handheld dynamometer (MIE, Medical Research Ltd., England) was used to measure IMS $(30,31)$. It is a valid and reliable measure tool .

Assessment procedures: All participants from both groups underwent the following assessments before and after physical therapy interventions.

Balance evaluation: The Biodex Balance System was used to evaluate balance performance. Participants centred themselves on the platform before starting the test. Participants were instructed to maintain this position while the investigator identified the participants' feet positions on the platform grid by recording the heel coordinates and foot angles $(18,27)$. All of these position values were recorded on the balance system's computer software (centred position of the patients). Each participant then assumed a standing position in their bare feet on the platform with open eyes and arms held at the sides for 20 seconds with a 10-second rest period between sets. The system was set at level 8 , which is constant instability. This system provided measurements of the overall stability index (OSI), the medial/lateral stability index
(MLSI) and the anterior/posterior stability index (APSI). These indices represent the variance of platform displacement in 360 degrees. The balance system was calibrated before each measurement and every participant was familiarised with it. Three trials were done and the mean values were reported as output results of the measurements (18).

\section{Functional activity evaluations}

Berg Balance Scale: The BBS includes 14 activities (balance tasks). Each participant was asked to perform functional activities such as sit-to-stand, stand-to-sit, and transfer; each of these tasks was measured on a 5-point ordinal scale ranging from $\mathrm{o}$ to 4 ( $\mathrm{o}=$ unable to perform, 4 = independent). The sub-test scores were summated to achieve a total score ranging from 0 to 56 . Higher scores indicated a better performance $(6,20,28)$.

Timed get-up-and-go test: Each participant was asked to take a standing position from a comfortable sitting position on an armchair. The participant was asked to walk three meters, turn, and return to the chair. Each person did this task three times and the mean values of the total time were calculated. Fewer minutes indicated a better performance $(4,22)$.

Isometric muscle strength: IMS is characterised by maximal contractions against an immovable resistance. A handheld dynamometer was 
used to measure the IMS of the lower limb antigravity muscles $(30,31)$. The IMS of the hip extensors was measured by keeping a handheld dynamometer against the middle of the back of the tested thigh from a prone lying position. Knee extensors were measured by keeping a handheld dynamometer against the tested leg from the sitting position at the edge of the plinth. IMS of the ankle plantarflexors was measured by keeping a handheld dynamometer against the tested plantar surface from the supine lying position with the feet outside of the bed. Each participant was asked to exert a maximum voluntary contraction against a stationary handheld dynamometer. Each test was done three times for each muscle group and the readings were recorded and the mean values were calculated $(4,30,32)$.

\section{Treatment procedures}

All participants from both groups practiced a prescribed multi-dimensional exercise program (booklets were distributed to all participants). The program mainly concentrated on balance exercises, functional activities, posture exercises and strength training for the antigravity muscles of the lower limbs (33).

Group-I: Twenty participants practiced on the prescribed exercise program under direct supervision for 35 to 45 minutes, two times per week for four months. Each session started with five minutes of warming up and finished with five minutes of cooling down (stretching exercises for the lower limbs and para-spinal muscles were performed for five repetitions with a 20-second hold for each muscle group) (4, 8, 34). In addition, there was a stimulus phase that focused on muscle strength, coordination and functional balance training.

First month: All of the following exercises were performed for 10 repetitions. Weight bearing exercises (e.g. standing on heels, fingertips [5-10 times] and mini-squat standing against the wall) were performed. Strengthening exercises were performed for hip extensors, knee extensors and ankle plantarflexors with 20\% 1RMax (low intensity with the pre-determined individualized muscular strength) (14) Walking exercises were done on an indoor track for five minutes. Postural exercises with specific emphasis on the the head, neck and trunk were included. Functional activities were done $3-5$ times for each activity (e.g. sit-to-stand and reaching tasks in all directions). Balance and coordination exercises were done 5-10 times.
Weight shifting was performed twice in each direction with the right and left foot in the standing position with movements performed 2-4 times anteriorly-posteriorly and laterally, tandem standing was done 2-3 times and for each foot at the front and one-leg standing 2-3 times on each foot $(4,8,14,35,36)$.

Second month: All previously mentioned exercises were performed for 10 repetitions with some modifications $(4,8,14,35,36)$. Strengthening exercises were done with 50\% of the 1RMax (moderate intensity with the predetermined individualised muscular strength) (14).

Third month: All previously mentioned exercises were performed for 10 repetitions with progression $(4,8,14,35,36)$. Strengthening exercises were performed with $20 \%$ of the 1 RMax (14) (muscles strength was re-measured to determine the new resistance after the first two months).

Fourth month: All previously mentioned exercises were performed for 10 repetitions with more modifications $(4,8,14,35,36)$. Strengthening exercises were performed with $50 \%$ of the 1RMax of the re-measured muscles strength after the first two months (14).

Group-II: Twenty participants practiced on the prescribed exercise program at home (not under direct supervision) for 35 to 45 minutes, two times per week for four months. Each participant was given a detailed booklet for the training program $(8,12)$ and adjustable sandbags of different sizes and weights. A researcher physical therapist visited each participant in the nursing home to provide instructions on how to properly perform the exercise program and how to make appropriate progressions of the exercises. All participants were contacted by phone once a week to enhance their participation and to answer any questions they had $(8,12)$. The participants received follow-up visits by the therapists working in the nursing homes as well as two home visits each month from the author. Participants may have done the recommended exercises in their own rooms, by walking in the garden and by doing household activities (4).

\section{Statistical Analysis}

The collected data were statistically analysed using SPSS (Version 22.0) in the form of descriptive and inferential analysis. The 
Original Article | Supervised versus home exercise programs on older subjects

repeated-measures analysis of covariance was used to evaluate the effects of supervised and home exercise programs within each group. It was also used to compare the mean values of all measured variables between the two groups in addition to using age and sex as confounders. Pearson's Chi-square and independent $t$-tests were used to compare demographic data of both groups. Statistical significance was determined at a $P$-value $<0.05$ and a confidence interval at $95 \%$.

\section{Results}

After the start of the study, one participant (who had a recent stroke) gave up attending the supervised exercise program and two participants in the home exercise program failed to complete the study program (one participant's condition had deteriorated by diabetes and the second failed to come to the final evaluation due to a change of residence) (Figure 1). As a result of these three excluded participants, the data from 37 participants were used for analysis in both the supervised exercise program $(n=19)$ and the home exercise program $(n=18)$. There were non-significant differences in demographic data for all participants before the physical therapy interventions (Tables 1a and b).

Exercise adherence: The adherence rate for participants was $89.14 \%$ and $84.20 \%$ in the supervised and home exercise programs respectively. This rate ranged from 25 to 31 sessions in the supervised program and from 24 to 30 sessions in the home program.

The Biodex balance indices and BBS significantly improved after both the supervised and home exercise training programs. The mean values for OSI, MLSI and APSI were reduced significantly during the standing position with open eyes $(P=0.004,0.007,0.004$ and 0.028 , 0.049, 0.030 in Group-I and Group-II, respectively) (Tables 2). The mean values of the BBS increased significantly from 31.79 (1.08) to 32.89 (1.69) and from 32.17 (1.04) to 34.17 (1.69) $(P=0.002$ and 0.001 in Group-I and Group-II, respectively).

Table 1a. Demographic data of all participants

\begin{tabular}{|c|c|c|c|c|c|c|c|c|}
\hline \multirow{2}{*}{ Variables } & \multicolumn{2}{|c|}{ Age / years } & \multicolumn{2}{|c|}{ Height /meter } & \multicolumn{2}{|c|}{ Weight/Kgm } & \multicolumn{2}{|c|}{$\mathrm{BMI} / \mathrm{Kg} / \mathrm{m}^{2}$} \\
\hline & Gr-I & Gr-II & Gr-I & Gr-II & Gr-I & Gr-II & Gr-I & Gr-II \\
\hline Mean & 69.16 & 68.33 & 1.74 & 1.76 & 82.47 & 81.05 & 27.38 & 27.24 \\
\hline SD & 4.28 & $3 \cdot 31$ & 0.05 & 0.05 & 4.06 & 4.81 & 1.12 & 1.01 \\
\hline$t$-value & \multicolumn{2}{|c|}{0.65} & \multicolumn{2}{|c|}{-1.24} & \multicolumn{2}{|c|}{0.97} & \multicolumn{2}{|c|}{0.39} \\
\hline$P$-value & \multicolumn{2}{|c|}{0.518} & \multicolumn{2}{|c|}{0.224} & \multicolumn{2}{|c|}{0.338} & \multicolumn{2}{|c|}{0.693} \\
\hline
\end{tabular}

The data are reported in mean, standard deviation of the two groups using the independent samples $t$ - test. Abbreviations: BMI: Body mass index; Gr-I: Group-I; Gr-II: Group-II; SD: standard deviation; Kgm: Kilogram; $\mathrm{Kg} / \mathrm{m}^{2}$ : Kilogram/meter square. Non-significant at $P$-value $>0.05$.

Table 1b. Demographic data of all participants

\begin{tabular}{|c|c|c|c|c|}
\hline Variables & $\begin{array}{l}\text { Group-I } \\
(n=19)\end{array}$ & $\begin{array}{l}\text { Group-II } \\
(n=18)\end{array}$ & Chi-square & $P$-value \\
\hline $\begin{array}{l}\text { Chronic diseases ( } n \& \%) \\
\text { One disease affection } \\
\text { Two diseases affection } \\
\text { Three diseases affection }\end{array}$ & $\begin{array}{c}3(15 \cdot 79) \\
13(68.42) \\
3(15 \cdot 79)\end{array}$ & $\begin{array}{l}3(16.67) \\
11(61.11) \\
4(22.22)\end{array}$ & $0.283^{\mathrm{a}}$ & 0.868 \\
\hline $\begin{array}{l}\text { Medications used ( } n \& \%) \\
\text { One drug } \\
\text { Two drugs } \\
\text { Three drugs }\end{array}$ & $\begin{array}{c}4(21.05) \\
11(57.89) \\
4(21.05)\end{array}$ & $\begin{array}{c}4(22.22) \\
10(55 \cdot 55) \\
4(22.22)\end{array}$ & $0.275^{\mathrm{a}}$ & 0.872 \\
\hline $\begin{array}{l}\text { Assistive devices ( } n \& \% \text { ) } \\
\text { Non-used } \\
\text { Indoor used } \\
\text { Outdoor used }\end{array}$ & $\begin{array}{l}10(15 \cdot 79) \\
3(15 \cdot 79) \\
6(31.58)\end{array}$ & $\begin{array}{l}9(50.0) \\
5(27.78) \\
4(22.22)\end{array}$ & $0.032^{\mathrm{a}}$ & 0.984 \\
\hline
\end{tabular}

The data are reported by using the percent and the Pearson Chi-square test a.

Abbreviations: $n$ : number. Non-significant at $P$-value $>0.05 . \%$ : Percentage 
Table 2. Pre and post mean values of Biodex balance indices of both supervised and home exercise programs

\begin{tabular}{|c|c|c|c|c|c|c|c|c|c|c|c|c|}
\hline \multirow{3}{*}{ Variables } & \multicolumn{6}{|c|}{ Supervised program } & \multicolumn{6}{|c|}{ Home program } \\
\hline & \multicolumn{2}{|c|}{ OSI } & \multicolumn{2}{|c|}{ APSI } & \multicolumn{2}{|c|}{ MLSI } & \multicolumn{2}{|c|}{ OSI } & \multicolumn{2}{|c|}{ APSI } & \multicolumn{2}{|c|}{ MLSI } \\
\hline & pre & post & pre & post & pre & post & pre & post & pre & post & pre & post \\
\hline Mean & 8.01 & 7.47 & $7 \cdot 74$ & 7.16 & 7.47 & 6.89 & 7.94 & $7 \cdot 50$ & 8.80 & 7.61 & 7.72 & $7 \cdot 33$ \\
\hline $\mathrm{SD}$ & 1.05 & 1.02 & 0.73 & 0.96 & 0.77 & 0.74 & 0.05 & 0.92 & 0.84 & 0.85 & 0.75 & 1.03 \\
\hline M differ & \multicolumn{2}{|c|}{0.53} & \multicolumn{2}{|c|}{0.58} & \multicolumn{2}{|c|}{0.59} & \multicolumn{2}{|c|}{0.44} & \multicolumn{2}{|c|}{0.39} & \multicolumn{2}{|c|}{0.38} \\
\hline $95 \% \mathrm{CI}$ & \multicolumn{2}{|c|}{$\begin{array}{l}0.19 \\
0.86\end{array}$} & \multicolumn{2}{|c|}{$\begin{array}{l}0.17 \\
0.98\end{array}$} & \multicolumn{2}{|c|}{$\begin{array}{l}0.21 \\
0.95\end{array}$} & \multicolumn{2}{|c|}{$\begin{array}{l}0.05 \\
0.83\end{array}$} & \multicolumn{2}{|c|}{$\begin{array}{l}0.02 \\
0.77\end{array}$} & \multicolumn{2}{|c|}{$\begin{array}{l}0.04 \\
0.73\end{array}$} \\
\hline F-statistic & \multicolumn{2}{|c|}{10.84} & \multicolumn{2}{|c|}{9.07} & \multicolumn{2}{|c|}{10.78} & \multicolumn{2}{|c|}{5.79} & \multicolumn{2}{|c|}{$4 \cdot 50$} & \multicolumn{2}{|c|}{$5 \cdot 59$} \\
\hline$P$-value & \multicolumn{2}{|c|}{0.004} & \multicolumn{2}{|c|}{0.007} & \multicolumn{2}{|c|}{0.004} & \multicolumn{2}{|c|}{0.028} & \multicolumn{2}{|c|}{0.049} & \multicolumn{2}{|c|}{0.030} \\
\hline
\end{tabular}

The mean values of Biodex balance indices and significance within each group were determined using repeated measure analysis of covariance.

Abbreviations: APSI: antero-posterior stability index; CI: Confidence interval; MLSI: medo-lateral stability index; M differ: Mean differences; OSI: overall stability index; Significant at $P$-value $<0.05$.

The mean values of the TUG test were significantly reduced only after the supervised program from 23.47 (0.84) to 21.95 (1.22) seconds $(P=0.001)$, whereas in Group-II, the time was reduced non-significantly from 23.39 (0.85) to $23.17(0.98)$ seconds $(P=0.260)$.

The mean values of IMS of the right ankle plantarflexors, right hip and knee extensor muscles increased significantly only after the supervised exercise training program $(P=0.001)$, whereas it increased nonsignificantly after the home exercise program $(P>0.05)$ (Table 3).

The repeated-measure analysis of covariance showed there were non-significant differences in the mean values of the three
Biodex balance indices (OSI, APSI and MLSI) after both the supervised and home exercise training programs $(P=0.954,0.174$ and 0.200 , respectively). There were significant differences in the mean values of the functional activities including the BBS and TUG $(P=0.040$ and 0.049, respectively) in addition to the IMS of the right ankle plantarflexors, knee extensor and hip extensor muscles $P=0.045,0.041$ and 0.040 , respectively) (Table 4).

There were non-significant differences in the mean values of all balance indices, functional activities and IMS between the supervised and home exercise programs with regard to age and sex covariates for all participants $(P>0.05)$.

Table 3. Pre and post mean values of isometric muscle strength of both supervised and home exercise programs

\begin{tabular}{|c|c|c|c|c|c|c|c|c|c|c|c|c|}
\hline \multirow{3}{*}{ Variables } & \multicolumn{6}{|c|}{ Supervised program } & \multicolumn{6}{|c|}{ Home program } \\
\hline & \multicolumn{2}{|c|}{ Rt Ankle } & \multicolumn{2}{|c|}{ Rt Knee } & \multicolumn{2}{|c|}{ Rt Hip } & \multicolumn{2}{|c|}{ Rt Ankle } & \multicolumn{2}{|c|}{ Rt Knee } & \multicolumn{2}{|c|}{ Rt Hip } \\
\hline & pre & post & pre & post & pre & post & pre & post & pre & post & pre & post \\
\hline Mean & 21.79 & 24.67 & 27.97 & 34.44 & 27.42 & 33.55 & 21.69 & 21.77 & 27.89 & 28.20 & 27.28 & $27 \cdot 51$ \\
\hline $\mathrm{SD}$ & 2.58 & 1.47 & 5.16 & 2.97 & $4 \cdot 46$ & 3.94 & 2.51 & 2.49 & 5.64 & 5.26 & 4.95 & 4.85 \\
\hline M differ & \multicolumn{2}{|c|}{-2.89} & \multicolumn{2}{|c|}{-6.47} & \multicolumn{2}{|c|}{-6.12} & \multicolumn{2}{|c|}{-0.08} & \multicolumn{2}{|c|}{-0.31} & \multicolumn{2}{|c|}{-0.22} \\
\hline $95 \%$ CI & \multicolumn{2}{|c|}{$\begin{array}{l}-3.72 \\
-2.03\end{array}$} & \multicolumn{2}{|c|}{$\begin{array}{l}-7.97 \\
-4.97\end{array}$} & \multicolumn{2}{|c|}{$\begin{array}{c}-7.45 \\
-4.8\end{array}$} & \multicolumn{2}{|c|}{$\begin{array}{c}-0.49 \\
0.33\end{array}$} & \multicolumn{2}{|c|}{$\begin{array}{c}-0.63 \\
0.25\end{array}$} & \multicolumn{2}{|c|}{$\begin{array}{c}-0.48 \\
0.04\end{array}$} \\
\hline F-statistic & \multicolumn{2}{|c|}{51.28} & \multicolumn{2}{|c|}{72.92} & \multicolumn{2}{|c|}{105.25} & \multicolumn{2}{|c|}{0.18} & \multicolumn{2}{|c|}{3.79} & \multicolumn{2}{|c|}{3.29} \\
\hline$P$-value & \multicolumn{2}{|c|}{$<0.001$} & \multicolumn{2}{|c|}{$<0.001$} & \multicolumn{2}{|c|}{$<0.001$} & \multicolumn{2}{|c|}{0.675} & \multicolumn{2}{|c|}{0.068} & \multicolumn{2}{|c|}{0.087} \\
\hline
\end{tabular}

The mean values of isometric muscle strength and differences within each group were determined with repeated measure analysis of covariance for both supervised and home groups.

Abbreviations: APSI: antero-posterior stability index; CI: Confidence interval; MLSI: medo-lateral stability index; OSI: overall stability index; M differ: Mean differences 
Original Article | Supervised versus home exercise programs on older subjects

Table 4. Comparison of balance indices, functional activities and muscle strength of both supervised and home exercise programs

\begin{tabular}{ccccccccc} 
Variables & OSI & APSI & MLSI & BBS & TUG & Rt Ankle & Rt Knee & Rt Hip \\
M differ & -0.026 & -0.45 & -0.44 & 1.27 & 1.22 & 2.89 & 6.52 & 6.25 \\
$95 \%$ CI & -0.68 & -1.05 & -1.33 & 1.96 & 2.40 & 1.54 & 3.72 & 3.41 \\
& -0.62 & -0.15 & 0.16 & $(0.47)$ & $(0.14)$ & 4.25 & 9.32 & 9.09 \\
F-statistic & 0.03 & 1.93 & 1.70 & 4.58 & 4.18 & 4.15 & 0.02 & 4.54 \\
$P$-value & 0.954 & 0.174 & 0.200 & 0.040 & 0.049 & 0.045 & 0.041 & 0.040 \\
\hline
\end{tabular}

The mean values of balance indices, functional activities and muscle strength and differences between both groups were determined with repeated measure analysis of covariance.

Abbreviations: APSI: antero-posterior stability index; BBS: Berg Balance Scale; TUG: Timed get up \& go test; OSI: overall stability index; MLSI: medo-lateral stability index

\section{Discussion}

The core of the exercise training program used in the current study was easy, safe, feasible, effective and applicable for older subjects, which constituted the most important criteria of exercise prescription for older subjects $(3,12$, $13,18,20)$. In addition, the prescribed exercise program was multi-dimensional and included muscular strength, coordination, and functional and balance training, which are considered the standard training recommendations for older subjects $(15,16)$. This concept is supported by many previous clinical studies that have reported that multifaceted interventions are very important for older participants in order for them to get the greatest benefits in balance, physical activity, functional mobility and reductions in falling risks $(10,17,22,37)$.

In the current study, consistent with other studies, balance performance, functional activities and IMS were measured as outcomes $(5,7,16,23,31,38)$. The results showed nonsignificant differences between both groups before physical therapy interventions, whereas the balance performance and functional activities significantly improved after both supervised and home exercise programs. These improvements supported the findings of many previous studies $(17,18,20,39)$. Balance training for eight weeks (20) or 12 weeks (18) increased balance in older participants. Also, recent studies have shown that both resistive and aerobic activities for 12 months achieved positive influences on functioning maintenance (17) and a reduced risk of falling among older individuals (39).

Improvements in balance and various other functions in older participants after an exercise intervention may be due to enhancements of various physiological components including sensory (e.g. proprioception, vision, and vestibular systems) and effectors like hip, knee and ankle strength, range of motion, and central processing (e.g. time to perturbations) $(6,9,40-$ 43).

The current study compared the effectiveness of a supervised exercise program with a home exercise program in older participants. The authors found non-significant differences between the two programs in balance performance. This may be due to the fact that the home exercise program was well constructed and had the same exercises included in the supervised program, but it was applied in nursing homes and not under direct supervision. Both programs included activities for muscle strength, coordination, and functional and balance training. In addition, there were followup contacts to all participants in the home program by phone once per week with two home visits every month for all participants. The main target of the follow-up visits was to enhance participation and adherence for maintaining the proper intensity of exercises in addition to answer inquiries from the participants. Many studies have applied multi-dimensional homebased programs (a combination of flexibility, balance and walking exercises) $(8,12,13)$. The authors found that a supervised homebased program for six weeks was safe and was associated with improvements in physical- and exercise-related outcome measures in older adults (13). Consequently, the effects of exercise and its feasibility may vary with the patient's degree of frailty, the format and intensity of the exercise intervention and the level of supervision $(12,13)$.

Either supervised or home exercise programs may improve the functional activities (BBS) of older people $(3,4,25)$. Others have combined supervised training with home exercise programs and found that this can 
improve balance and reduce the falling rates of older adults $(23,24)$. Therefore, older subjects need to participate in well-constructed exercise programs or at least should be supplemented with a well-organized group of instructions and exercises to practice at home. Thus, when a home program is well designed and has a good level of follow up, it can achieve satisfactory improvements in balance in older subjects.

In contrast with the current findings, some authors have found that supervised programs are more effective in reducing the risk factors of falling among older participants living in nursing homes $(3,4,25)$. The current study used longer multi-dimensional programs for four months, whereas in the Donat and Ozcan (4) study, the authors applied a shorter program for only eight weeks. Furthermore, the outcome measurements of the two studies were different. In another comparative study, the author compared an extensive supervised program versus a short home-based program. They found the supervised combination of balance and strength with power training improved performance among older participants (3). The supervised program in the Gschwind et al. (3) study was 12 weeks of exercise intervention, but the home exercises were applied with less frequency and controlled on a weekly basis by phone calls to the participants. In contrast, the current home program included the same exercises as the supervised program. Every participant was provided a detailed booklet of the training program with instructions for how to properly perform the home exercises, which were supported by weekly phone calls and home visits twice per month for all participants.

The other findings in the current study included improvements in the TUG and IMS of the lower limbs, which significantly improved only after the supervised exercise program. This suggests that the supervised exercise program was superior and more effective than the home exercise program in improving TUG and IMS of the lower limbs $(8,44)$. Nelson et al. (8) applied a multi-dimensional home-based program on an elderly population in a community dwelling for six months. While the program was safe and could improve functional activities, there were only non-significant changes in muscle strength and endurance (8). However, it was reported that interventions for older participants should be specifically targeted to improve functional activities and reduce the risk of falling. Increases in the muscular strength of older participants are an additional target to confirm improvements in functional activities for older participants. The non-significant increases in muscle strength after a home exercise program may be due to certain limiting factors and barriers in performing the exercises accurately, as they were performed with the supervised program (8). There are some barriers that have been reported in the literature. The relationship between the barriers and exercise participation has also been reported $(25,32)$. The supervisor identified eight barriers significantly associated with a decreased adherence rate to a home exercise program including a lack of interest, competition, poor health, lack of strength, fear of falling, shortness of breath, and low outcome expectations (32). In addition, the insufficient intensity of the interventions and lack of follow up in nursing homes may be a limiting factor (25).

\section{Conclusion}

Both the supervised and home exercise programs significantly increased balance performance. The supervised exercise program was superior to the home exercise program in restoring functional activities including BBS and TUG as well as IMS of the lower limbs in older participants.

\section{Limitations}

Unfortunately, this study was limited by a relatively small number of patients. Exercise interventions were carried out for only four months and were very limited. Measurements were performed only before and after treatments without any long-term follow-up examinations.

\section{Recommendations}

Motivation in older participants is essential to practicing a regular balance exercise program. It is preferable that it be conducted in a safe and controlled environment. There should be greater encouragement for the establishment of community-based group exercise training programs. Additional studies are needed with larger sample sizes using different training programs and prolonged follow-up examinations. Several objective assessment tools are recommended to improve postural control and to prevent falls in frail older individuals. 
Original Article | Supervised versus home exercise programs on older subjects

\section{Acknowledgement}

The authors are grateful to the all participated patients and physical therapists for their patience and valuable co-operation.

\section{Conflict of Interest}

None

\section{Funds}

None

\section{Authors' Contribution}

Conception and design: AAES, EFY

Analysis and interpretation of the data: AAES, EFY

Drafting of the article: AAES, EFY

Critical revision of the article for important intellectual content: AAES, EFY

Final approval of the article: AAES, EFY

Provision of study materials or patients: AAES, EFY

Statistical expertise: AAES

Obtaining of funding: AAES, EFY

Administrative, technical, or logistic support: EFY

Collection and assembly of data: AAES, EFY

\section{Correspondence}

Dr. Alsayed Abd elhameed Shanb

BSc, MSc, PhD (Faculty of Physical Therapy,

Cairo-University)

Associate Professor of Physical Therapy

Physical Therapy Department,

College of Applied Medical Sciences,

University of Dammam

King Fahd Street, Alkhobar, PO Box 3496, 32256

Dammam City, Kingdom of Saudi Arabia

Tel:+966555786349

Fax: +9663330343

E-mail: aashanb@uod.edu.sa

\section{References}

1. Carlson J. CME article: Role of physical activity in the prevention of disability for older persons. Clinical Geriatric. 2000;7:24-32.

2. Alfieri FM, Riberto M, Abril-Carreres A, BoldóAlcaine M, Rusca-Castellet E, Garreta-Figuera R. Effectiveness of an exercise program on postural control in frail older adults. Clinical Interventions in Aging. 2012;7:593-598. http://dx.doi.org/ 10.2147/CIA.S36027.
3. Gschwind YJ, Kressig RW, Lacroix A, Muehlbauer T, Pfenninger B. A best practice fall prevention exercise program to improve balance, strength/ power, and psychosocial health in older adults: study protocol for a randomized controlled trial. BMC Geriatrics. 2013;13:105-110. http://dx.doi. org/10.1186/1471-2318-13-105.

4. Donat A, Ozcan A. Comparison of the effectiveness of two programs on older adults at risk of falling: unsupervised home exercise and supervised group exercise. Clinical Rehabilitation. 2007;21:273-283. http://dx.doi. org/10.1177/0269215506069486.

5. Lord SR, Menz HB, Tiedemann A. A physiological profile approach to falls risk assessment and prevention. PhysTher. 2003;83:237-252. http:// dx.doi.org/ptjournal.apta.org/content/83/3/237.

6. Jacobson BH, Thompson B, Wallace $\mathrm{T}$, Brown L, Rial C. Independent static balance training contributes to increased stability and functional capacity in community-dwelling elderly people: A randomized controlled trial. Clin Rehabil. 2011;25(6):549-556. http://dx.doi. org/10.1177/0269215510392390.

7. Rubenstein LZ. Clinical risk assessment, interventions and services. Falls in older people: epidemiology, risk factors and strategies for prevention. Age and Ageing. 2006;35-S2:ii37ii41. http://dx.doi.org/10.1093/ageing/aflo84 ii37.

8. Nelson ME, Layne JE, Bernstein MJ, Nuernberger A, Castaneda C, Kaliton D. The effects of multi-dimensional home-based exercise on functional performance in elderly people. The Gerontological Society of America. 2004;59A(2):154-160.

9. Alfieri FM, Riberto M, Gatz LS, Ribeiro CPC, Lopes JAF, BattistellaL R. Functional mobility and balance in community-dwelling elderly submitted to multisensory versus strength exercises. Clin Interv Aging. 2010;5:181-185. http://dx. doi.org/10.2147/CIA.S10223.

10. Howe TE, Rochester L, Jackson A, Banks $\mathrm{PMH}$, and Blair VA. Exercise for improving balance in older people. Cochrane Database Syst Rev. 2011;9(11):CDoo4963. http://dx.doi. org/10.1002/14651858.CDoo4963.pub3. 
11. Thomas S, Mackintosh S, Halbert J. Does the Otago exercise program reduces mortality and falls in older adults? A systematic review and meta-analysis. Age Ageing. 2010;39:681-687. http://dx.doi.org/10.1093/ageing/afq102.

12. Hinrichs T, Bucchi C, Brach C, Wilm S. Feasibility of a multi-dimensional home-based exercise program for the elderly with structured support given by the general practitioner's surgery: Study protocol of a single arm trial preparing an RCT. BMC Geriatrics. 2009;9:37. http://dx.doi. org/10.1186/1471-2318-9-37.

13. Matsuda PN, Shumway-Cook A, Fapt A, Ciol MA. The effects of a home-based exercise program on physical function in frail older adults. $J$ Geriatr Phys Ther. 2010;33:78-84. http://dx.doi. org/10.2522/ptj.20090100.

14. Orr R, de Vos NJ, Singh NA, Ross DA, StavrinosTM, Fiatarone-Singh MA. Power training improves balance in healthy older adults. The Journals of Gerontology Series A. 2006;61(1): 78-85. doi: 10.1093/gerona/61.1.78.

15. Shubert TE. Evidence-based exercise prescription for balance and falls prevention: A Current review of the literature. $J$ Geriatr PhysTher. 2011;34:100-108. http://dx.doi.org/10.1519/ JPT.obo13e31822938ac.

16. Theou O, Stathokostas L, Roland KP, Jakobi JM, Patterson C, Vandervoort AA. The effectiveness of exercise interventions for the management of frailty: A systematic review. Journal of Aging Research. 2011;2011:1-9. http://dx.doi. org/10.4061/2011/569194.

17. Roma MF, Busse AL, Betoni RA, Melo AC, Kong J, Santarem JM. Effects of resistance training and aerobic exercise in elderly people concerning physical fitness and ability: a prospective clinical trial. Einstein (Sao Paulo). 2013;11(2):153-157. http://dx.doi.org/10.1590/S1679-450820130002 oooo3.

18. Gusi N, Adsuar JC, Corzo H, DePozo Cruz B, Olivares PR, Perraca JA. Balance training reduces fear of falling and improves dynamic balance and isometric strength institutionalized older people. A randomized trial. Journal of Physiotherapy. 2012;58:97-104.
19. Rosendahl E, Gustafson Y, Nordin E, LundinOlsson L, Nyberg L. A randomized controlled trial of fall prevention by a high-intensity functional exercise program for older people living in residential care facilities. Aging Clin Exp Res. 2008;20(1):67-75. http://dx.doi.org/10.1007/ BFo3324750.

20. Bulat T, Hart-Hughes S, Ahmed S, Quigley P, Palacios P, Werner DC. Effect of a group-based exercise program on balance in elderly. Clinical Interventions in Aging. 2007;2(4):655-660.

21. Bastone AC, Filho WJ. Effect of an exercise program on functional performance of institutionalized elderly. $J$ Rehabil Res Dev. 2004;41:659-668.

22. Hasegawa $R$, Monirul Islam $M$, Nasu $E$, Tomiyama N, Chul Lee S, Koizumi D . Effects of combined balance and resistance exercise on reducing knee pain in community-dwelling older adults. Physical \& Occupational Therapy in Geriatrics. 2010;28(1):44-56. http://dx.doi. org/10.3109/02703180903381086.

23. Barnett A, Smith B, Lord SR, Williams M. Baumand A. Community-based group exercise improves balance and reduces falls in at-risk older people: a randomized controlled trial. Age and Ageing. 2003;32:407-414. http://dx.doi. org/10.1093/ageing/32.4.407.

24. DeVito CA, Morgan RO, Duque M. Physical performance effects of low-intensity exercise among clinically defined high-risk elders. Gerontology. 2003;49:146-154. http://dx.doi. org/10.1159/oooo69168.

25. Day L, Fildes B, Gordon I. Randomized factorial trial of fall prevention among older people living in their own homes. BMJ. 2002;325:128-133. http://dx.doi.org/10.1136/bmj.325.7356.128

26. American Geriatrics Society British Geriatrics Society, and American Academy of Orthopaedic Surgeons Panel on Falls Prevention. Guideline for the prevention of falls in older persons. $J \mathrm{Am}$ Geriatr Soc. 2001;49:664-672. http://dx.doi. org/10.1046/j.1532-5415.2001.49115.x.

27. Ahmed AF. Effect of sensorimotor training on balance in elderly patients with knee osteoarthritis. Journal of Advanced Research. 2011;2:305-311. http://dx.doi.org/10.1016/j.jare. 2011.02.001. 
Original Article | Supervised versus home exercise programs on older subjects

28. Langley FA, Mackinto SF. Functional balance assessment of older community dwelling adults: A systematic review of the literature. I JAHSP. 2007;5(4):1-11. http://ijahsp.nova.edu.

29. Pereira VV, Maia RA, Silva SM. The functional assessment Berg Balance Scale is better capable of estimating fall risk in the elderly than the post-urographic balance stability system. Arq Neuro-psiquiatr. 2013;71(1):5-10. http://dx.doi. org/10.1590/Soo04-282X2013000100003.

30. Piva SR, Goodnite EA, Childs JD. Strength around the hip and flexibility of soft tissues in individuals with and without patella-femoral pain syndrome. J Orthop Sports PhysTher. 2005;35:793-801. http://dx.doi.org/10.2519/jospt.2005.2026.

31. Katoh M, Isozaki K, Sakanoue N, Miyahara T. Reliability of isometric knee extension muscle strength measurement using a hand-held dynamometer with a belt: A study of test-retest reliability in healthy elderly subjects. JPhys Ther Sci. 2010;22:4-12. http://dx.doi.org/10.1589/ jpts.26.1855. Epub 2014 Dec 25.

32. Ibrahim, AI, Muaidi QI, Abdelsalam MS, Hawamdeh ZM, Alhusaini AA. Association of postural balance and IMS in early and middleschool-age boys. Journal of Manipulative and Physiological Therapeutics. 2013;36(9):633643. http://dx.doi.org/10.1016/j.jmpt.2013.08. 009.

33. Forkan R, Pumper B, Smyth N, Wirkkala H, Ciol MA, Shumway-Cook A. Exercise adherence following physical therapy intervention in older adults with impaired balance. Phys Ther. 2006;86:401-410. http://ptjournal.apta.org/ content/86/3/401.

34. Burton E, Lewin G, Clemson L, Boldy D. Effectiveness of a lifestyle exercise program for older people receiving a restorative home care service: a pragmatic randomized controlled trial. Clinical Interventions in Aging. 2013;8:15911601. doi: 10.2147/CIA.S44614

35. Hruda KV, Hicks AL, McCartney N .Training for muscle power in older adults: effects on functional abilities. Canadian Journal of Applied Physiology. 2003;28(2):178-189. http://dx.doi. org/10.1139/ho3-014.
36. Bruunsgaard H, Bjerregaard E, Schroll M, Pedersen BK. Muscle strength after resistance training is inversely correlated with baseline levels of soluble tumor necrosis factor receptors in the oldest old. Journal of the American Geriatrics Society. 2004;52(2):237-241. http://dx.doi. org/10.1111/j.1532-5415.2004.52061.x.

37. Meuleman JR, Brechue WF, Kubilis PS, Lowenthal DT. Exercise training in the debilitated aged: strength and functional outcomes. Arch. Phys. Med. Rehabil. 2004;81(3):312-318. http://dx.doi.org/10.11648/j.cmr.20130202.12.

38. Wolf B, Feys H, Weerdt WD. Effect of a physical therapeutic intervention for balance problems in the elderly: a single-blind, randomized, controlled multicenter trial. Clin Rehabil. 2001;1:112-120. http://dx.doi.org/10.1191/o269215501cr456oa.

39. Ambrose TL, Khan KM, Eng JJ. Resistance and agility reduce fall risk in women aged 75 to 85 with low bone mass: a 6-month randomized, controlled trial. J Am Geriatr Soc. 2004;52:657665. http://dx.doi.org/10.1111/j.1532-5415.2004. 52200.x.

40. Rogers, M.E, Rogers, NL, Takeshima N. Balance training in older adults. Journal of Aging and Health. 2005;1:475-486. http://dx.doi. org/10.2217/1745509X.1.3.475.

41. Cyarto E, Brown W, Marshall A, Trost S. Comparative effects of home-and group-based exercise on balance confidence and balance ability in older adults: cluster randomized trial. Gerontology. 2008;54:272-280. http://dx.doi. org/10.1159/ooo155653.

42. Iwamoto J, Suzuki H, Tanaka K. Preventative effect of exercise against falls in the elderly: a randomized controlled trial. Osteoporosis Int. 2009;20:1233-1240. http://dx.doi.org/10.1007/ s00198-008-0794-9.

43. Kita K. Musculoskeletal rehabilitation and bone. Static balance exercise for preventing falls and fractures. Clin Calcium. 2010;20:567-575. http://dx.doi.org/CliCa1004567575.

44. Hauer K, Rost B, Ruschle K. Exercise training and secondary prevention of falls in geriatric patients with a history of injurious falls. $J$ Am Geriatr Soc. 2001;49:10-20. http://dx.doi.org/10.1046/ j.1532-5415.2001.49004.x. 